\title{
Correction to: Hybrid Silicon Nanostructures with Conductive Ligands and Their Microscopic Conductivity
}

\author{
TIEZHENG BIAN, ${ }^{1}$ JAMIE N. PECK,${ }^{2}$ STEPHEN P. COTTRELL, ${ }^{2}$ \\ UPALI A. JAYASOORIYA, ${ }^{1}$ and YIMIN $\mathrm{CHAO}^{1,3}$ \\ 1.-School of Chemistry, University of East Anglia, Norwich NR4 7TJ, UK. 2.-ISIS Facility, \\ Rutherford Appleton Laboratory, Chilton, Didcot OX11 0QX, UK. 3.-e-mail: y.chao@uea.ac.uk
}

\section{Correction to: \\ Journal of ELECTRONIC MATERIALS, Vol. 46, No. 5, 2017 \\ https://doi.org/10.1007/s11664-016-4954-y}

Reviewing the results presented in Fig. 4(a) and (b) of this study together with the text discussing this figure, we have noticed that the apparent absence of clear $\Delta_{1}$ resonances in these solid-state spectra for these systems is not properly discussed in the article. We believe these resonances are, in fact, present in the data, and careful fitting of the spectra presented reveals broad, weak lines at approximately the position expected for a $\Delta_{1}$ resonance with $\mathrm{Mu}$ addition at $\mathrm{C} 7$ (see Table $\mathrm{I}$ in the paper). Their inclusion supports the original conclusions of the work; however, we were cautious about including these fits in the paper owing to the difficulty of separating these lines from the complex instrument background. The authors regret that this point was not adequately explained in the paper.

Publisher's Note Springer Nature remains neutral with regard to jurisdictional claims in published maps and institutional affiliations. 